\title{
O TRATAMENTO DE DOENTES NO HOSPITAL DE CABECEIRAS DE BASTO (1896-1930)
}

\author{
Norberto Tiago GONÇALVEZ FERRAZ \\ Mestre em Sociologia. Braga
}

\begin{abstract}
RESUMEN: Este artículo está basado en la tesis sobre la historia y acción social de la Santa Casa de Misericordia de la villa de Cabeceiras de Basto, hecha para el Maestrado de Sociología de la Familia y Solidariedades Sociales. Mostramos los cuidados de salud dados a los enfermos pobres, los resultados de su tratamiento y como era la rutina diaria en el hospital entre los años 1896 y 1930.

PALABRAS CLAVE: eniermos, hospital, Casa de Misericordia, tratamiento.

ABSTRACT: This article is based on the thesis about the story and social action of the Holy House of Mercy of the town of Cabeceiras de Basto, made in the master's degree of Sociology of Family and Social Solidarities. Here we focus on the health cares given to the poor sicks. We present their provenience, the results of their treatment and how was the daily routine on the hospital between 1896 and 1930.
\end{abstract}

KEYWORDS: sicks, hospital, Mercy, treatment.

Desde sempre que a actividade das Misericórdias esteve associada ao sector da saúde. Muito cedo construíram hospitais de raiz ${ }^{1}$ e também incorporaram muitos desses estabelecimentos já existentes ${ }^{2}$. A vontade de tratar dos enfermos em Cabeceiras de Basto, vila do distrito de Braga, Portugal, levou os irmãos a desejarem ter um hospital. É preciso, aliás, frisar que não há registo de que a Santa

${ }^{1}$ Ávila, J G. (1996). Santa Casa da Misericórdia da Vila das Velas, achegas para a sua história. Vila das Velas: Edição da Misericórdia das Velas, p. 9.

${ }^{2}$ Sobre o processo das incorporações leia-se ABreu, L. (2000). “A especificidade do sistema de assistência pública português, linhas estruturantes”. Arquipélago, História, p. 429. 
Casa tenha ajudado doentes nas suas residências ${ }^{3}$, cingindo assim a sua assistência no campo da saúde, ao hospital.

\section{O PERFIL DOS DOENTES DO HOSPITAL}

Inaugurado a dois de Fevereiro de 1896, o hospital tinha por objectivo o que ficara definido nas reuniões inaugurais da fundação da Santa Casa da Misericórdia: ser um local para recolhimento dos pobres doentes do concelho e fora dele, tal como ainda dos irmãos da Misericórdia que se achassem reduzidos ao estado de pobreza, como já anteriormente tivemos oportunidade de referir. Estava também aberto para os que quisessem ser tratados em quartos particulares, ou seja, aqueles que não eram pobres e que podiam pagar o seu internamento e tratamento. Os irmãos da Misericórdia que quisessem ser tratados como particulares nesses quartos gozariam de uma diminuição de preço face aos que não fossem irmãos, e de modo geral, tinham sempre preferência de entrada. A Santa Casa distinguiu com gestos de solidariedade os seus membros, demonstrando que os que trabalhavam para os pobres eram merecedores dessa distinção.

Para o estudo dos doentes internados no hospital da Misericórdia servimo-nos do único livro de doentes existente para a época em estudo. Este livro começa no dia da inauguração e prossegue até 1900 (1896-1900), sendo útil para estudar as moléstias e o perfil dos doentes atendidos no hospital. Infelizmente, ele não distingue explicitamente entre os doentes que eram recebidos e tratados gratuitamente como pobres daqueles que eram tratados como particulares e que tinham de pagar o tratamento.Durante os quatro anos abarcados foram atendidos 168 doentes no hospital, os quais foram considerados como a nossa amostra para o universo de todos os enfermos. Embora sabendo que estes quatro anos apenas se representam a si próprios, não quisemos privar o leitor do conhecimento destes resultados. Atente-se, pois, no quadro seguinte, para se conhecer o perfil dos doentes tratados nas suas enfermidades:

Quadro $n^{\circ}$ 24. Profissão dos doentes (1896-1900)

\begin{tabular}{lc}
\hline Profissão & $N^{o}$ de doentes \\
\hline Jornaleiro & 77 \\
Pedreiro & 5 \\
Caseiro & 10 \\
Criado de lavoura & 7
\end{tabular}

\footnotetext{
${ }^{3}$ Leia-se para este assunto MonTEIRo, B. R. (2006). O fenómeno de desospitalização e as suas interconexões familiares, comunitárias e sociais., Braga: Instituto de Ciências Sociais tese de doutoramento policopiada, p. 41,
} 


\begin{tabular}{lc} 
Almocreve & 1 \\
"Mendigo" & 9 \\
Pintor & 1 \\
Carpinteiro & 5 \\
Criado de servir / serviçal & 15 \\
Sapateiro & 4 \\
Doméstica & 3 \\
Soldado & 7 \\
"Prostituta encoberta" & 1 \\
Criada de cozinha & 5 \\
Tecedeira & 1 \\
Enfermeiro & 1 \\
Caseira e lavadeira & 1 \\
Condutor & 1 \\
Alfaiate & 1 \\
Proprietário & 1 \\
Músico & 1 \\
Lavrador & 2 \\
Cultivador & 1 \\
Costureira & 1 \\
Sem profissão/não mencionada & 7 \\
\hline Total & 168 \\
\hline
\end{tabular}

Fonte: ASCMCB. Livro de doentes 1896-1900, fls. 1-29.

Os sete indivíduos mencionados como "sem profissão" eram crianças ainda muito pequenas e um idoso que já não trabalhava. É preciso, contudo, referir que existe o registo de mais menores como sendo enfermos do hospital, mas todos esses tinham já uma profissão, como criados ou ajudantes dos pais. Tratava-se de uma realidade social diferente da actualidade, na qual as crianças começavam a trabalhar cedo, pois, no agregado familiar era necessário que todos contribuíssem desde tenra idade para cobrir as despesas básicas ${ }^{4}$.

Estudando os dados apresentados, vemos que o grupo social que mais recorria ao hospital para internamento e tratamento era o dos jornaleiros com quase metade das ocorrências. Esta é uma realidade que é corroborada por outros estudos no país vizinho $^{5}$. Os jornaleiros eram pagos ao dia de trabalho sendo, assim, um grupo

${ }^{4}$ Veja-se para este tema Rosas, F. (1994). “O Estado Novo”. En Mattoso, J. (eds.), História de Portugal vol. VII. Lisboa: Círculo de Leitores, p. 54.

${ }^{5}$ Goméz Rodriguez, M. S. (1995). El Hospital de la Misericórdia de Toledo en el siglo XIX. Toledo: Instituto provincial de investigaciones y estúdios toledanos, pp. 108-109. 
social conotado com a dependência e a pobreza, dependendo sempre dos donos de terras e grandes lavradores os quais os contratavam para "jorna”. Os jornaleiros eram contratados conforme os desejos dos proprietários ${ }^{6}$, não tendo evidentemente nenhuma segurança laboral ${ }^{7}$. Não possuíam mais do que a sua força de trabalho que vendiam. Revelador da precária situação deste grupo dos jornaleiros, é a definição dada no livro dos óbitos do hospital, onde duas falecidas foram mencionadas como sendo ao mesmo tempo "jornaleiras" e também "indigentes". Dado o seu carácter de pobreza seriam um problema em termos de controlo de propagação de doenças ou epidemias, até porque os cuidados sanitários e preocupações higiénicas deste grupo deviam ser mínimas ou inexistentes, ao que se juntavam as más condições de habitabilidade em que viviam ${ }^{8}$. Tinham também uma alimentação cheia de carências onde o pão, alimento base, era frequentemente de fraca qualidade. O salário não lhes permitia comer carne fresca ${ }^{9}$. Com muita facilidade os jornaleiros regressavam à condição de pobres e à precisarem de receber auxílio. A precariedade em que viviam e a dependência que tinham colocava-os frequentemente em estado de pobreza e, por conseguinte, eram dos principais grupos a precisarem de ajuda no século XIX ${ }^{10}$.

Assim, reuniam todas as características e preocupações que as elites fundadoras do hospital tinham em mente. Ajudar um grupo pobre e precário com acções de caridade e filantropia, recolhendo-os em caso de enfermidade, e controlar um potencial grupo transmissor de doenças, o qual representaria um "perigo" para os grupos sociais para quem trabalhavam. Como refere Maria Antónia Lopes os

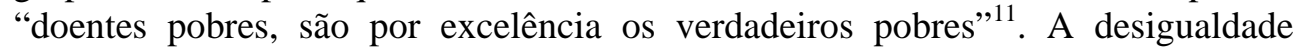
social entre ricos e pobres era considerada necessária para que os ricos pudessem

${ }^{6}$ O’ Neill, B. J. (1984). Proprietários, lavradores e jornaleiros: desigualdade social numa aldeia transmontana, 1870-1978. Lisboa: Dom Quixote, pp. 32,109.

${ }^{7}$ Veja-se Carasa Soto, P. (1991). História de la beneficência en Castilla y Leon. Poder y pobreza en la sociedad castelhana. Valladolid: Universidad de Valladolid, pp. 110-111.

${ }^{8}$ Consulte-se PEÑa GonZalez, P. (1993). La salud y la enfermedad en Huelva en el siglo XIX (1800-1880). Huelva: Diputacion Provincial de Huelva, p. 100.

${ }^{9}$ PeÑa GonZalez, P. (1993). La salud y la enfermedad en Huelva en el siglo XIX (1800-1880). Huelva: Diputacion Provincial de Huelva, p. 61.

10 Leia-se Carasa Soto, P. (1987). "Câmbios em la tipologia del pauperismo en la crisis del Antiguo Régimen”. Investigaciones históricas. Valladolid: Universidad de Valladolid, p. 141.

${ }^{11}$ Confira-se Lopes, M. A. (1999). Pobreza, assistência e controlo social em Coimbra (17501850), vol. II. Coimbra: Palimage Editores, p. 726. 
praticar a beneficência e alcançar a salvação ${ }^{12}$, exercendo uma relação de paternalismo sobre as classes pobres populares.

A sua predominância é tão óbvia que quase deixa na sombra outros grupos sociais que recorriam também ao hospital. No entanto, é importante referir alguns desses outros grupos sócio-profissionais que eram atendidos no estabelecimento. Alguns deles eram casos isolados de pessoas que tinham uma profissão a qual não as deixaria enquadrar-se no caso de "enfermos pobres". É preciso notar que um pobre que quisesse ser tratado no hospital como tal, para não ter de pagar o seu tratamento, tinha que "comprovar devidamente o seu estado de pobreza"13. Estes indivíduos, (enfermeiro, músico, alfaiate, sapateiro, lavrador, pintor, almocreve, condutor, pedreiro, costureira, soldado) entravam na categoria de doentes tratados que pagavam o seu tratamento? Não podemos responder a esta questão com segurança e devemos ser cuidadosos na resposta. Se tomarmos como exemplo um dos doentes que deu entrada, ele foi classificado como "mendigo", embora anteriormente tivesse sido alfaiate, facto que demonstra um percurso de mobilidade social descendente acentuado. Maria Antónia Lopes revela-nos que em Coimbra existiam alfaiates, sapateiros, pintores e pedreiros que eram assistidos como pobres $^{14}$. Logo, o estatuto destes indivíduos é incerto e demonstra que a pobreza é uma realidade em movimento, que não é estática. Prova ainda que uma faixa grande da população se encontrava num estado que podia com facilidade passar à condição de pobre. Mas se tomarmos em consideração que, segundo a mesma autora, só quando muito pobres, os indivíduos por ela estudados em Coimbra entre os séculos XVIII-XIX, aceitavam ser internados, preferindo o tratamento domiciliário pelo médico ${ }^{15}$, podemos então deduzir que a grande maioria destes indivíduos com profissão diversa e assistidos no hospital de Cabeceiras seria também pobres. A excepção foram os soldados que, nas suas deslocações dentro do território, tinham de recorrer ao hospital mais próximo onde se encontrassem, quando nas imediações não houvesse um hospital militar.

12 Leia-se CARASA Soto, P. (2004). "Beneficência y cuestion social: una contaminacion aracaizante”. Historia Contemporânea. Valladolid: Serviço Editorial de la Universidad del País Vasco, p. 135.

13 ASCMCB. Livro das actas e deliberações da Santa Casa da Misericórdia de S. Miguel de Refojos $n^{\circ} 1$ 1890-1902, fl. 46.

14 Consulte-se Lopes, M. A. (1999). Pobreza, assistência e controlo social em Coimbra (17501850), vol. II. Coimbra: Palimage Editores, p. 874.

${ }^{15}$ Lopes, M. A. (1999). Pobreza, assistência e controlo social em Coimbra (1750-1850), vol. II. Coimbra: Palimage Editores, p. 726. 
Se muitos destes grupos profissionais se resumem a um pequeno número de "ocorrências", mais importante parece ser a variedade dos "criados": "as criadas de cozinha, criados de lavoura e criados de servir ou serviçais". Todos juntos representam 16\% dos doentes tratados entre 1896 e 1900 . A presença dos serviçais e criados nos hospitais está confirmada em outros estudos ${ }^{16}$. Eram homens e mulheres que serviam geralmente dentro de casa das famílias com mais posses ou então trabalhavam nas terras e quintas destas. Alimentados e alojados por seus amos, não ganhavam muitas vezes o suficiente para as suas necessidades e recorriam à caridade. Sabemos que na Idade Moderna não era raro os criados serem tratados à custa de seus senhores em casa ${ }^{17}$. Assim, estes serviçais e criados que aparecem entre os doentes do hospital da Misericórdia de Cabeceiras não iriam para o estabelecimento se os seus amos cuidassem deles ${ }^{18}$, ou então, seriam internados quando os seus quadros clínicos o exigiam. Portanto, seriam certamente recolhidos como pobres apresentando o comprovativo respectivo.

Para além do grande grupo de jornaleiros que eram atendidos no hospital, temos ainda mais dois grupos sociais que também estão nessa condição e que vale a pena serem referidos, pois, têm algum peso no número de ocorrências: os caseiros com 10 ocorrências e os mendigos com nove ocorrências. Estes últimos representam os mais desprotegidos da sociedade, os mais pobres da escala social. No que diz respeito à sociedade encontravam-se num estado de total exclusão: não tinham qualquer rendimento para além das esmolas que por compaixão recebiam e muitos não tinham sequer uma residência. Logo, em caso de doenças, seriam o estrato mais desprotegido e com menos meios para lhes poder resistir. Para estes, a entrada e o internamento no hospital seria até mesmo uma forma de terem alimentação e repouso que noutro caso lhes estaria vedado, algo que também sucederia com os jornaleiros, os quais teriam uma deficiente alimentação. As solidariedades estabelecidas com estes grupos mais desfavorecidos tinham um significado mais profundo, pois, para além dos pobres estes grupos encontravam-se totalmente desprotegidos e a necessitarem do atendimento das casas de caridade. Recorde-se o caso do alfaiate que teve de mendigar para prover ao seu sustento, como já ficou

${ }^{16}$ Veja-se a propósito GomÉz Rodriguez, M. S. (1995). El Hospital de la Misericórdia de Toledo en el siglo XIX. Toledo: Instituto provincial de investigaciones y estúdios toledanos, pp. 108109; Lopes, M. A. (1999). Pobreza, assistência e controlo social em Coimbra (1750-1850), vol. II. Coimbra: Palimage Editores, p. 872.

${ }^{17}$ CorreiA, F. S. (1943). “A assistência médica em Portugal durante o século XVI”. Imprensa Médica, p. 22.

${ }^{18}$ Consulte-se Lopes, M. A. (1999). Pobreza, assistência e controlo social em Coimbra (17501850), vol. II. Coimbra: Palimage Editores, p. 873. 
assinalado. Estranha-se apenas que não fossem mais ainda os casos de mendigos tratados no hospital. Seriam esquivos ao tratamento? Teriam receio que no hospital fossem mais controlados pelas autoridades públicas? Ou o hospital teria relutância em internar este tipo de doentes como acontecia na Idade Moderna, isto por considerar que podiam trabalhar? De facto, ainda no século $\mathrm{XX}$, um mendigo que pudesse trabalhar era punido como um vadio ${ }^{19}$. É que, por exemplo, no caso deste mendigo que fora antes alfaiate, o seu internamento no hospital não foi de moto próprio, mas sim por ordem do administrador do concelho de Cabeceiras de Basto, pois o seu estado (acabou por falecer mais tarde) devia ter sido considerado muito grave e provavelmente um problema para a saúde pública. Os mendigos, deambulando por diferentes terras onde pediam esmola, eram também motivo de preocupação no que respeita à propagação de doenças ${ }^{20}$.

Já os caseiros estavam em melhor situação que os mendigos. Quando trabalhavam nas quintas e em anos de boas colheitas, podiam viver de forma modesta, mas, evidentemente, passavam também por dificuldades. Em anos de más colheitas, ou em casos de propriedades que dessem poucos rendimentos, ficando a maior parte da produção para os proprietários, os caseiros encontravam-se em situação mais difícil. Sem dúvida, que também estavam perto da pobreza e não era raro passarem a pobres. $\mathrm{O}$ facto de ser registado o caso de uma caseira tratada no hospital que era também lavadeira, indica que em muitos casos o ser caseiro era insuficiente para garantir a sustentação de uma pessoa e não raras vezes acumulavam funções para aumentarem os seus rendimentos. Como sabemos a falta de especialização era uma característica destes grupos sociais, sendo o problema mais grave nas mulheres, que por esta razão auferiam também salários mais baixos e estavam mais expostas às flutuações do mercado laboral. Por conseguinte, cumpriam várias ocupações em simultâneo.

Em suma, o hospital cumpria a sua função ajudando os pobres na doença. Os jornaleiros, os mendigos, os caseiros e os criados, eram os grupos sociais que mais recorriam ao estabelecimento de saúde e dele esperavam solidariedade. Uma massa social a que era necessário dar atenção por piedade religiosa e espírito filantrópico.

Os indivíduos que podiam ser atendidos como particulares eram minoritários nas estatísticas do hospital, pois, não só este não se dirigia em primeiro lugar para eles, mas também porque, podendo, preferiam, com certeza, ser atendidos em casa

${ }^{19}$ PINTO, M. F. (1999). Os indigentes entre a assistência e a repressão, a outra Lisboa no $1^{\circ}$ terço do século. Lisboa: Livros Horizonte, p. 105.

${ }^{20}$ A propósito destes pobres veja-se Fernandes, P. G. C. (1994). "Os vadios de início do século (1901-1906)”. Revista da Faculdade de Letras. História, pp. 333-347. 
pelo médico municipal. Cremos que recorreriam ao hospital em caso de urgência, como para uma operação, depois de algum acidente grave.

Por exemplo, merece especial referência, como caso único, uma senhora internada em 20 de Outubro de $1898^{21}$, por ser de um estatuto social superior e que aqui foi tratada. Esta senhora é o único caso, entre 1896 e 1900, de uma "proprietária” internada no hospital. Ora, o ser "proprietária” reporta-nos a um estrato social superior. Ela possuiria terras que lhe davam rendimento e onde trabalhariam caseiros, criados de lavoura ou até jornaleiros. Ou seja, estaria a ser tratada no mesmo estabelecimento onde muito provavelmente eram cuidados os seus empregados e trabalhadores, ainda que, quase de certeza, num quarto particular. Este aspecto não é de menor relevo, pois, o facto de estar num espaço separado dos restantes doentes conferia-lhe maior dignidade e simbolizava a sua capacidade financeira. O certo é que se a Misericórdia era uma casa de prontosocorro especialmente para os pobres, podia também vir a ser para os ricos que num futuro incerto dela precisassem ${ }^{22}$.

Esta doente após dois meses de tratamento hospitalar, saiu em vinte de Dezembro de 1898. Chama-nos a atenção o motivo pelo qual ela pediu para sair do hospital, não estando ainda recuperada, totalmente: fê-lo para poder passar o Natal com a sua família. Parece ser indicador de alguém de um grupo social já com outras preocupações, onde os rituais se viviam em grupo e neste caso junto de familiares.

\section{AS DOENÇAS}

As doenças que mais preocupam cada sociedade e época em que ocorrem vão variando. A elas se podem juntar ainda os períodos de fome que atingiam largas camadas de população. Novamente, recorrendo ao livro de doentes do hospital de 1896-1900 podemos traçar um quadro das principais doenças que atingiram a população internada na Misericórdia cabeceirense na passagem do século XIX para o XX:

Quadro $n^{\circ} 29$. Doenças dos enfermos (1896-1900)

\begin{tabular}{lc}
\hline Anos de 1896-1900 / Doenças & $N^{o}$ de ocorrências \\
\hline Abcessos vários & 3 \\
Albuminúria & 1 \\
& \\
& ${ }^{21}$ ASCMCB. Livro de doentes 1896-1900, fls. 18v.-19. \\
& ${ }^{22}$ CALADO, R. S. (1936). Origens e vida da Santa Casa da Misericórdia de Torres Vedras. Torres \\
Vedras: Santa Casa da Misericórdia de Torres Vedras, p. 12.
\end{tabular}


Alienação mental

Amenorreia $\quad 6$

Amiotrofia de membros $\quad 1$

Anasarca 1

Anemia $\quad 17$

Nefrite $\quad 5$

Reumatismo

Ascite $\quad 1$

Impetigo 1

Astenia Geral

Blenorragia $\quad 1$

Bronquite Crónica 3

Cachexia 3

Cálculos hepáticos $\quad 1$

Cancros Venéreos $\quad 1$

Cancro do colo do útero $\quad 1$

Cloro-anemia $\quad 8$

Leucorreia 1

Conjuntivite $\quad 1$

Linfatismos 3

Ferimentos, fracturas, contusões, contracturas 18

Diarreia 4

Dores de barriga e estômago 2

Disenteria 3

Gangrena $\quad 1$

Úlceras em várias zonas do corpo 11

Dismenorreia 2

Dispepsia 13

Furúnculos 1

Eczema 4

Edema 3

Enterite $\quad 6$

Nevralgia 1

Escrofulas 5

Febres (simples e intermitentes) 3

Febre tifóide $\quad 1$

Gastralgia $\quad 6$

Dores nas pernas 1

Gastrite 2

Gastroenterite 2

Hemiplegia $\quad 2$

Hidropisia 3

Humores frios 1

Icterícia 1 
$\begin{array}{lr}\text { Inanição } & 1 \\ \text { Inchaços } & 1 \\ \text { Tosse } & 1 \\ \text { Influenza } & 2 \\ \text { Lesão cardíaca } & 1 \\ \text { Metrite } & 1 \\ \text { Uretrite } & 1 \\ \text { Nevrostenia } & 1 \\ \text { Obstipação } & 1 \\ \text { Otorreia } & 1 \\ \text { Pleurisia } & 1 \\ \text { Pneumonia } & 5 \\ \text { Tuberculose } & 5 \\ \text { Úlcera no estômago } & 1 \\ \text { Úlcera fungosa no dorso } & 1 \\ \text { Não mencionada / ilegível } & 20\end{array}$

Fonte: ASCMCB. Livro de Doentes 1896-1900, fls. 1-29.

A lista de doenças tratadas é bastante longa, embora algumas sejam semelhantes entre si. De notar que o número de ocorrências aqui não corresponde ao número total de doentes. Isto deve-se ao facto de vários destes doentes apresentarem não apenas uma, mas duas ou três enfermidades diagnosticadas quando deram entrada no hospital. Também sucedeu o mesmo doente ser internado repetidas vezes no estabelecimento. Das quatro ocorrências de eczema registadas, três delas referemse a uma menina de 10 anos que num curto espaço de tempo foi tratada de um “eczema crónico”.

O leque alargado de doenças exigia dos profissionais de saúde uma grande atenção e cuidado, não apenas nos tratamentos médicos, como também em termos alimentares.

Constata-se também uma diferença assinalável na frequência de doenças. Se algumas se registavam poucas vezes, outras apresentaram uma forte incidência. A doença mais frequente foi a anemia, falando precisamente da debilidade em que se encontravam os corpos. As questões ligadas à cirurgia estiveram também presentes através de diversos ferimentos, fracturas e contusões, com 18 casos.

Os problemas de digestão (dispepsias) constituem outra enfermidade assinalável, com 13 casos, logo seguidos das úlceras ou chagas à superfície do corpo com 11 casos a que se pode juntar ainda uma úlcera no dorso. Com menor incidência, mas ainda a merecer que sejam mencionadas estão a amenorreia, enterite, gastralgia, com seis casos, e ainda o reumatismo, nefrite, astenia geral, 
"escrofulas”, pneumonia e tuberculose com cinco casos registados. Algumas doenças encontraram terreno mais fácil de propagação em alguns grupos sociais. As anemias são o reflexo de uma má ou deficiente alimentação, que conduz a falta de glóbulos vermelhos no sangue. O resultado é um estado de fraqueza e debilidade geral do indivíduo. O mesmo, quase se pode dizer que uma “astenia geral” também ela caracterizada por um estado de fraqueza geral.

Aliás, os problemas relacionados com a alimentação parecem ser o maior mal de que padeciam estes enfermos. Dispepsias, gastralgias, e enterites dizem todas elas respeito ao aparelho digestivo. Fosse por digestão (dispepsia), ou dores e inflamações em órgãos do sistema digestivo (gastralgia e enterite), a frequência com que estes problemas se registaram fazem supor uma alimentação, para além de pobre, muitas vezes desequilibrada e não variada, com problemas de higiene mesmo, o que resultaria em problemas desta ordem. Outra doença, a amenorreia, especifica das mulheres, pode também ser devida a uma fraca alimentação.

Importantes eram ainda os casos de ferimentos, fracturas e contusões. A natureza perigosa de algumas profissões, conjugada com poucas ou nenhumas medidas de segurança que na altura se tomavam, conduziam a esta situação. Por exemplo, um pedreiro ficou ferido no rosto aquando de um rebentamento de pólvora num penedo, em Setembro de 1896. Um rapaz criado de lavoura teve uma "ferida contusa de couro cabeludo, com descolamento deste em grande extensão e hemorragia $^{23}$. Se o rapaz saiu curado, já o pedreiro ficou cego de um olho.

As chagas (úlceras) de que muitos padeciam podiam ser resultantes de feridas que não cicatrizavam por falta de nutrientes ou pelos inexistentes hábitos de higiene das classes mais pobres. Já referenciamos as grandes pragas epidémicas de fins do século XIX e inícios do século XX, das quais se destacava a tuberculose. $\mathrm{O}$ hospital registou cinco casos desta doença a que se juntam mais cinco de "escrofulas”, doença que derivava da tuberculose. O carácter específico desta doença, os cuidados que se tinham com ela e até algum receio que ela incutia, estão reflectidos no destino que alguns destes doentes tiveram. Alguns deles faleceram. Houve alguns casos de sucesso, talvez devido ao estado menos adiantado e gravoso da doença.

Mais interessante é ter-se verificado ordem de saída aos enfermos quando eles continuavam doentes. Por exemplo, uma mendiga jovem de 22 anos que sofria de "escrofulas”, teve de sair por "não ter cura a sua doença”"24. O hospital, após um

${ }^{23}$ ASCMCB. Livro de doentes 1896-1900, fls. 12v.-13.

${ }^{24}$ ASCMCB. Livro de doentes 1896-1900, fls. 11v.-12. 
internamento de mais de dois meses, optou por fazer sair esta doente. Como se justifica esta medida? A resposta, pensamos que se encontra precisamente no receio que esta doença inspirava nas pessoas. Ou estaria também o médico mesmo convencido da ineficácia dos tratamentos ministrados? Dois destes doentes tiveram ordem de saída explicada pelos responsáveis hospitalares. Um jovem "condutor" saiu por "não ser curável a doença e ser contagiosa"25. Já uma criada de servir de 34 anos "saiu a ares por não ter cura e ser prejudicial ao hospital" ${ }^{26}$. Note-se que no passado os hospitais não permitiam o internamento de pessoas com doenças contagiosas, precisamente pela facilidade com que infectariam a restante população internada ${ }^{27}$.

Como se sabe, e perante os surtos de tuberculose foi necessário criar hospitais especializados no tratamento desta doença - os sanatórios. Os portadores desta doença eram encaminhados para estes estabelecimentos e não para os hospitais comuns. Todavia, compreende-se que alguns tenham ingressado no hospital de Cabeceiras. Meio pequeno e distante dos hospitais especializados, aceitou alguns doentes, mas tratou de os fazer sair quando não experimentavam melhoras. Assim o médico, enfermeiros e demais responsáveis tinham receios fundamentados. Sendo pobres, tinham que estar recolhidos nas enfermarias gerais do hospital em contacto com pessoas com outras doenças. Ora, tratando-se de uma doença contagiosa e muitas vezes mortal, os profissionais de saúde temiam que, estando os tuberculosos internados sem apresentarem melhorias sensíveis, a sua doença se espalhasse a outros doentes internados, ocasionando uma epidemia interna incontrolável. É mesmo possível que temessem pela sua própria saúde. Assim, quando não se viam melhoras possíveis e previsíveis ao fim de algum tempo, preferiam que estes doentes saíssem e fossem “a ares” para terem algum tratamento. Mandar ir "a ares" aos tuberculosos era uma das medidas recomendadas. Consistia em encaminhar estes enfermos para regiões, no campo e perto da natureza, onde pudessem respirar "ares mais puros", do que aqueles que existiam nas povoações e, com isso, terem hipóteses de cura.

As doenças mais comuns no hospital ${ }^{28}$ se, por um lado, eram o reflexo de alguns dos principais problemas de saúde da época, como a tuberculose, por outro,

${ }^{25}$ ASCMCB. Livro de doentes 1896-1900, fls. 16v.-17.

${ }^{26}$ ASCMCB. Livro de doentes 1896-1900, fls. 20-21v.

27 Araújo, M. M. L. (2003). “O hospital do Espírito Santo de Portel na época moderna”. Cadernos do Noroeste, p. 356.

${ }^{28}$ Doenças do foro digestivo, infecções (úlceras) e problemas respiratórios como a tuberculose parecem ser de facto os que mais afectavam a população pobre. Veja-se PEÑa GonZALEz, P. (1993). 
reflectiam os grupos sociais que maioritariamente recorriam ao hospital: pobres, que padeciam de doenças derivadas de fraca nutrição a qual estava associada à sua condição de pobreza ${ }^{29}$. O estado de fraqueza era mais um problema para estas pessoas, pois, acabava por as impossibilitar de poderem usar todas as suas forças, sendo na sua maioria jornaleiros, como vimos. A doença acabava por se repercutir no trabalho. Os proprietários e os grandes lavradores preferiam trabalhadores saudáveis. Incapacitados para servirem de criados e de jornaleiros, estes podiam ser facilmente despedidos ${ }^{30}$. Por isso, não era raro tentarem “esconder” algumas maleitas para poderem ganhar o “pão do dia a dia”. Camuflando-as e continuando a trabalhar, a doença ganhava mais força e debilitava-os cada vez mais. Estes pobres acabavam por se encontrar num dilema: ou assumir a doença, podendo ser despedidos, e procurar curar-se ou continuar a trabalhar até as forças o permitirem, deixando-a avançar e aumentando a debilidade do corpo.

As considerações efectuadas aproximam-nos do mundo dos pobres quando adoeciam. O internamento hospitalar representava para eles a necessidade de se adaptarem a um contexto que os obrigava ao descanso, que não conheciam, mas também ao cumprimento de regras e a hábitos de higiene a que não estavam habituados. A chamada de atenção dum mesário a uma doente que algumas vezes encontrou na cozinha, prova que os mesmos não se circunscreviam às enfermarias e que procuravam outros espaços. Noutra ocasião, um outro irmão de mês disse ter sido informado da insubordinação de um doente, situação que era urgente resolver. Tudo isto demonstra o desenquadramento em que estes doentes se encontravam, quando recolhiam ao hospital. Esta resistência pode ainda estar associada ao facto das enfermarias do hospital nunca terem estado completamente cheias. O valor máximo de doentes diários referido pelos irmãos, entre 1902 e $1909^{31}$, que visitaram o hospital em cada mês foi de oito enfermos, quando o hospital teria capacidade para atender 15 em simultâneo. Seja como for, as dúvidas dos pobres em se recolherem ao hospital existiriam quer em face do que expusemos, quer por terem dificuldades em arranjar transporte até ao local ou ainda por darem mais crédito à medicina e receitas populares e dos curandeiros. Houve mesmo um

La salud y la enfermedad en Huelva en el siglo XIX (1800-1880). Huelva: Diputacion Provincial de Huelva, p. 126; CARAsA Soto, P. (1991). História de la beneficência en Castilla y Leon. Poder y pobreza en la sociedad castelhana. Valladolid: Universidad de Valladolid pp. 118-119.

${ }^{29}$ CARASA Soto, P. (1991). História de la beneficência en Castilla y Leon. Poder y pobreza en la sociedad castelhana. Valladolid: Universidad de Valladolid pp. 118-119.

${ }^{30}$ Consulte-se para esta matéria LOPEs, M. A. (1999). Pobreza, assistência e controlo social em Coimbra (1750-1850), vol. II. Coimbra: Palimage Editores , p. 873.

${ }^{31}$ ASCMCB. Livro das visitas dos irmãos de mês ao Hospital 1902-1909, fls.1-12. 
internado que fugiu do hospital e outros doentes pediram para sair por vontade própria. Esta atitude também não é inédita. Na Idade Moderna, alguns hospitais conheceram a mesma situação.

Também é compreensível que os doentes pedissem para regressarem a casa, quando se sentiam um pouco melhores. Muitos seriam chefes de família e sabiam que o sustento da célula familiar dependia do rendimento do seu trabalho. Por isso, quando se viam aliviados dos males que os atormentavam, solicitavam autorização para regressar a casa. Uma doente não quis submeter-se a uma operação quando sofria de um cancro do útero, indicando a resistência a tratamentos que envolviam um considerável risco de vida. O sucesso dos tratamentos hospitalares patenteia-se no quadro que em seguida apresentamos.

Quadro $n^{\circ}$ 30. Resultados do tratamento dos doentes (1896-1900)

\begin{tabular}{lc}
\hline \multicolumn{1}{c}{ Resultados obtidos } & $N^{o}$ de ocorrências \\
\hline Saiu bom/curado & 112 \\
Saiu convalescente/quase curado & 7 \\
Faleceu & 10 \\
Transferido para outro hospital & 6 \\
Saiu no mesmo estado & 1 \\
Saiu melhorado & 12 \\
Saiu em convalescença com tratamento incompleto a seu pedido & 3 \\
Saiu por não querer ser operado ou sujeitar-se a tratamentos & 5 \\
Saiu a seu pedido (estado de saúde não mencionado) & 2 \\
Saiu por a sua doença não ter cura & 4 \\
Fugiu do hospital durante o tratamento & 1 \\
Saiu bem, mas “com alguma mazela permanente” & 1 \\
Saiu “quase bom por não haver com que ultimasse o & 1 \\
tratamento" & \\
Saiu melhorado de parte das suas maleitas, mas devia continuar & 2 \\
tratamento noutro local & 168 \\
Saiu melhorado mas acabou por falecer algum tempo depois & \\
\hline Total & \\
\hline \hline
\end{tabular}

Fonte: ASCMCB. Livro de Doentes 1896-1900, fls. 1-29.

Os dados parecem não deixar grande margem para dúvidas no que diz respeito aos resultados obtidos no tratamento dos doentes. A maioria dos enfermos teve sucesso e recuperou das enfermidades de que sofria. Nas notas tomadas no livro de doentes, ora aparecia a referência a ter "saído bom”, ou a ter "saído curado". Na elaboração deste quadro optamos por juntar as duas referências, pois, parece-nos serem praticamente equivalentes entre si. 
A distância para o segundo resultado mais verificado é tão grande (mais de 100 ocorrências), que não podem restar grandes dúvidas. Sendo um estabelecimento relativamente pequeno e com recursos limitados, o hospital da Misericórdia de Cabeceiras de Basto tinha uma alta taxa de sucesso no tratamento dos seus doentes. Destes, 66,6\% saíram completamente curados. Para além dos curados, deve acrescentar-se aqueles que saíram em convalescença, os quais indiciam também melhoras e fazem uma percentagem de $10,7 \%$. Assim, a assistência prestada foi praticamente eficaz, ou pelo menos contribuiu para uma melhoria significativa do estado de saúde dos doentes.

Alguns, como vimos, quiseram sair a seu próprio pedido. Podiam sentir-se suficientemente restabelecidos para voltarem ao trabalho ou então recusarem-se a seguir os tratamentos, tomar os medicamentos ou sujeitar-se às operações que o médico prescrevia.

Os casos de falecimentos são poucos. Estes não devem ser vistos como fracassos, pois, alguns deles seriam de tal modo graves que dificilmente poderiam sobreviver. Na luta entre a vida e a morte nem sempre se ganha. E atendendo à dimensão da Misericórdia, estes valores de óbitos são realmente baixos. Dez óbitos em quatro anos. Ter-se-á mantido sempre assim? No único livro de óbitos existente, de 1911 a 1913, são apenas registados seis óbitos em dois anos. Assim, cremos que não se tratará de uma mera situação pontual, lembrando até que, em 1912, o hospital atendeu um número muito elevado de doentes. Como se sabe, o número de defuntos nos hospitais das Misericórdias portuguesas foi baixo mesmo na Idade Moderna. Esta percentagem está directamente relacionada com as doenças de que os enfermos eram portadores e com os serviços que lhes eram prestados. $\mathrm{O}$ conforto, o descanso, a higiene, uma melhor alimentação e os cuidados medicinais fortaleciam os corpos e combatiam a doença ${ }^{32}$.

Alguns insucessos também aconteceram. Vimos já aqueles em que o hospital mandava sair doentes, quando após tratamentos longos, sem que houvesse evolução ou melhorias significativas, tentando que houvesse uma outra saída para eles, como mandar “a ares”. Noutras situações, por falta de meios de tratamento, a instituição resolvia transferir os doentes para outros centros com mais recursos e melhor capacidade médica e técnica para tratar de certos problemas. Isto sucedia com doentes que necessitavam de operações cirúrgicas que não eram possíveis de executar num pequeno hospital. Também aconteceu terem sido transferidos

32 A propósito da clientela hospitalar e dos tratamentos que a mesma recebia nos hospitais da Idade Moderna leia-se ARAúJo, M. M. L. (2003). “O hospital do Espírito Santo de Portel na época moderna”. Cadernos do Noroeste, pp. 364-365, 377. 
soldados para um hospital militar. Em geral, os doentes transitavam para o hospital de São Marcos da Misericórdia de Braga, embora haja notícia da transferência de um doente para o hospital do Porto ${ }^{33}$. Braga tinha um hospital maior, era a capital de distrito e ficava mais perto. É, portanto, natural que se escoassem para este estabelecimento.

Apenas um caso nos parece indicar insucesso no tratamento. Trata-se de um indivíduo que saiu melhorado de uma úlcera, mas acabou por falecer pouco depois. Sabemos de outros casos de pessoas que também faleceram pouco depois de saírem do hospital. Nestes últimos casos eram pessoas que não quiseram submeter-se a tratamentos ou operações. Como no caso dos pobres, o tratamento era gratuito, não espanta que após apresentarem sinais de melhora os doentes tivessem "alta" se a pedissem. A Misericórdia estaria também interessada em reduzir os custos face aos meios limitados de que dispunha.

Ainda assim, esta falha não apaga a grande taxa de sucesso que o hospital observou no tratamento aos doentes. Como se explicam as taxas de sucesso? Cremos que residiam no perfil social dos doentes, no tipo de doença e nos tratamentos que recebiam. Já referimos que a sua dieta alimentar era pobre e debilitava as defesas dos seus organismos. Como assinala Fernando Rosas, os indivíduos das zonas rurais nortenhas padeciam de défices calóricos e proteicos, por não ingerirem a quantidade suficiente de que precisavam ${ }^{34}$. A situação era ainda mais grave quando sucediam crises agrícolas, pois este era o sector base de que dependiam estas pessoas ${ }^{35}$. Ora, quando eram recolhidos no hospital estes enfermos, para além de receberem cuidados médicos e medicação adequada, dispunham também de uma alimentação (a menos que a doença obrigasse a alguma dieta especial) a que de outro modo dificilmente teriam acesso. Para além de pão, vinho, leite, legumes, comiam carne de vaca e vitela, galinha e produtos de mercearia como massas e arroz. Uma alimentação robustecida, aliada aos medicamentos necessários era o passo para muitos destes doentes pobres e debilitados terem uma recuperação total. No estudo sobre a Misericórdia de Ponte da Barca, Maria das Dores Sousa Pereira refere que a boa alimentação prestada no

33 ASCMCB. Diário da Receita e Despesa da Misericórdia de São Miguel de Refojos nº 2, 19111920, fl. 93.

${ }^{34}$ Veja-se Rosas, F. (1994). “O Estado Novo”. En Mattoso, J. (eds.), História de Portugal vol. VII. Lisboa: Círculo de Leitores, p. 57.

${ }^{35}$ MaZa Zorilla, E. (1999). Pobreza y beneficência en la España contemporânea (1808-1936). Barcelona: Ariel Practicum, p. 12. 
hospital era um passo importante para a cura ${ }^{36}$. Ou, como concluiu Laurinda Abreu, os doentes pobres eram alguém para quem o simples repouso e o reforço das dietas alimentares eram, muitas vezes, o receituário milagroso para o seu total restabelecimento ${ }^{37}$. Podemos assim concluir, como Maria Antónia Lopes bem refere que "não se ia para o hospital para morrer"38.

Para manter a ordem e fazer o tratamento dos doentes, o hospital dispunha de funcionários e regulamentos para o seu funcionamento interno. É sobre esta organização e o dia-a-dia no hospital que falaremos em seguida.

\section{O QUOTIDIANO HOSPITALAR}

O dia no hospital começava bem cedo. Logo de manhãzinha, por volta das seis horas o enfermeiro levantava-se e, depois de se arranjar, abria a porta do hospital dirigindo-se em seguida às enfermarias. Acordava os doentes, limpava as enfermarias, despejava os urinóis e administrava os medicamentos segundo a primeira hora marcada pelo regulamento $(6 \mathrm{~h} 10 \mathrm{~m}$, mas cremos que podia ser mais tarde). O enfermeiro fazia as camas, substituindo quando necessário a roupa suja por uma lavada, e tratava de preparar os enfermos para a visita médica . Aos doentes era também prestada assistência ao nível da higiene. Existiam dois lavatórios de ferro e principalmente uma banheira para se poderem lavar. A temperatura da água era verificada com um termómetro.

Antes da visita médica ocorrer, às sete ou oito horas, o enfermeiro servia a primeira refeição do dia aos doentes já preparada pela cozinheira, a qual na época era chamada de "almoço". O leite devia ser fornecido bem cedo pelos produtores que viriam à porta do hospital com os seus animais ${ }^{39}$. Depois desta refeição, tudo era arrumado e o enfermeiro fazia as últimas tarefas para que tudo estivesse preparado para a visita do médico.

Este chegava pouco antes das dez horas para a visita diária. A sua primeira tarefa era examinar as pessoas que estavam à espera para serem atendidas,

${ }^{36}$ Confira-se PereIRA, M. D. S. (2003). Entre ricos e pobres: a actuação da Santa Casa da Misericórdia de Ponte da Barca (1630-1800). Braga: Universidade do Minho dissertação de mestrado policopiada, pp. 254-255.

37 ABreu, L. (2000). "A especificidade do sistema de assistência pública português, linhas estruturantes”. Arquipélago. História, p. 431.

${ }^{38}$ Consulte-se para este assunto a obra de LOPEs, M. A. (1999). Pobreza, assistência e controlo social em Coimbra (1750-1850), vol. II. Coimbra: Palimage Editores, p. 622.

39 O mesmo procedimento era adoptado em Setúbal. Veja-se ABREU, L. (1999). Memórias da alma e do corpo. A Misericórdia de Setúbal na modernidade. Viseu: Palimage Editores, p. 398. 
aguardando permissão para serem internados no hospital. Esperavam fora do edifício, por vezes, à chuva onde aguardavam que o hospital abrisse para serem atendidos $^{40}$. Este é um cenário possível, visto a porta do hospital ficar fechada durante a noite $^{41}$. No local de consulta, o médico avaliava a pessoa queixosa. $\mathrm{O}$ provedor ou o irmão do mês estaria também presente para darem despacho à entrada desses doentes, os quais teriam feito pedido prévio e apresentado comprovativo do seu estado de pobreza. Os doentes admitidos eram, então, conduzidos às enfermarias pelo enfermeiro, não sem antes terem entregue todas as suas roupas e espólio vestindo a "roupa de enfermo",42. Pensamos que não eram obrigados já a confessarem-se e a comungar como acontecia no passado nos hospitais das Misericórdias ${ }^{43}$. Se fossem tratados como "particulares", pagando o seu tratamento, eram conduzidos aos quartos privados, como acontecia em outros hospitais.

Após este trabalho, o médico dirigia-se às duas enfermarias e aos quartos privados para examinar os doentes que estavam internados. Ouvia as informações do enfermeiro sobre a evolução do estado de cada um e fazia as suas recomendações sobre os remédios a administrar, assim como fazia outras recomendações particulares sobre cada um deles.

Terminada a visita médica por volta das onze ou doze horas, caso fosse quartafeira ou domingo, chegava a altura de deixar entrar as pessoas que quisessem visitar os enfermos. O tempo de visita devia durar uma hora, pois, às 12 horas era servido o "jantar", correspondendo ao nosso almoço. Os doentes recebiam, então, a segunda refeição do dia, mais reforçada.

A parte da tarde era mais tranquila para os enfermos. Alguns que estivessem em melhores condições gostariam com certeza de abandonar a enfermaria e passear um pouco. Contudo, não tendo o hospital um local para poderem espairecer sob autorização médica, pouco mais lhes restava que manterem-se recolhidos na enfermaria. É possível que tentassem convencer os enfermeiros e a cozinheira a deixarem-nos ir à cozinha para poderem conversar. Sabemos que numa ocasião

${ }^{40}$ Assim se verificava também no hospital de São Marcos de Braga. Consulte-se CASTRO, M. F. (1998). “O Hospital de São Marcos, espaços e serviços”. Boletim do Hospital de São Marcos, p. 116.

${ }^{41}$ Veja-se AraúJo, M. M. L. (2003). “O hospital do Espírito Santo de Portel na época moderna”. Cadernos do Noroeste, p. 357.

${ }^{42}$ Desconhecemos em que consistia a indumentária dos pacientes.

43 Pereira, M. D. S. (2003). Entre ricos e pobres: a actuação da Santa Casa da Misericórdia de Ponte da Barca (1630-1800). Braga: Universidade do Minho dissertação de mestrado policopiada, p. 246. 
uma doente teve várias vezes acesso à cozinha, o que só se compreende com a conivência do enfermeiro ou da cozinheira. Cremos, no entanto, que, por norma, os funcionários tentariam que não houvesse transgressões, pois, podiam correr o risco de serem despedidos.

Durante a tarde os empregados podiam aproveitar para fazerem compras de remédios e géneros necessários para o tratamento e sustento dos enfermos, conforme lhes competia segundo o regulamento. É certo que alguns produtos chegavam dos produtores e fornecedores de carne e legumes, mas havia géneros necessários que se compravam numa padaria ou mercearia. É possível que se revezassem para não deixar o hospital completamente só. Note-se que estes géneros deviam, em princípio, ser fornecidos por produtores contratados em arrematação pública. Tal acontecia já, por exemplo, na Misericórdia de Braga ${ }^{44}$. Mas como das vezes que a Santa Casa tentou fazer essa arrematação em hasta pública nunca apareceu nenhum licitante, os fornecimentos de géneros e remédios eram adquiridos livremente pela irmandade a quem melhor a servisse. Mas que razões explicam esta falta de oferta de vendedores à confraria? Desconhecemos as razões, mas num meio pequeno onde todos eram conhecidos, estas atitudes poderiam contribuir para uma maior liberdade de actuação da Santa Casa sem "vigilância” apertada do poder político. Sem arrematação em hasta pública, a confraria usava de maior liberdade para adquirir os produtos de que necessitava a quem queria e como desejava.

Não sabemos se o irmão do mês também efectuava algumas dessas compras, quando visitava o hospital. Era ele que fazia a despesa necessária ao hospital durante o seu mês, recebendo no fim do mandato o pagamento das despesas feitas. O regulamento indicava que a ele competia mandar fazer as compras dos géneros para as despesas das enfermarias e não, proceder às compras.

Às três da tarde, quem quer que tivesse ido buscar remédios ou algum alimento, tinha de estar de volta, pois, era a hora prevista para a segunda administração de remédios. Os que apresentassem melhoras podiam andar a pé somente nas enfermarias e ao toque das "ave-marias”, o enfermeiro mandava que todos eles recolhessem às suas camas. Depois de todos se terem recolhido, o enfermeiro acendia as luzes dos candeeiros ou dos castiçais das duas enfermarias, antes que escurecesse totalmente. A iluminação era feita através de azeite, combustível mais barato do que a iluminação a gás, que o hospital de São Marcos adoptara em fins

\footnotetext{
44 Para este assunto confira-se CAstro, M. F. (2003). A Misericórdia de Braga. Braga: Santa Casa da Misericórdia e autora, pp. 411-425.
} 
do século XIX ${ }^{45}$. Este tipo de iluminação além de caro era de pouca qualidade, pelo que este hospital em breve o trocaria pela iluminação eléctrica. Em 1930, a Misericórdia cabeceirense também adoptou a iluminação eléctrica ${ }^{46}$.

Por volta das sete horas da tarde/noite, o enfermeiro servia uma ceia aos doentes, correspondendo ao nosso jantar. A esta hora, as portas do hospital estavam já encerradas. Tudo devia estar calmo e tranquilo após a refeição. A cozinheira recolhia-se aos seus aposentos, mas isso podia não suceder com os enfermeiros. A sua função, explicitada no regulamento de terem de velar de dia e de noite pelos doentes, podia obrigá-los a ter que dormir numa cama colocada numa das enfermarias caso o estado de saúde de algum internado necessitasse de uma intervenção rápida e urgente. Por outro lado, deviam estar atentos a que as luzes estivessem sempre acesas durante toda a noite, o que indica que o seu descanso não seria despreocupado. Por volta da meia-noite, o regulamento previa a hipótese de uma pequena refeição ser servida aos doentes, embora não saibamos se tal procedimento era adoptado no hospital em estudo.

Parte importante do tratamento eram as refeições. Convém, por conseguinte, analisá-las. O regulamento do hospital de Fafe (que o hospital de Cabeceiras adoptou) descreve com termos precisos as dietas alimentícias que deviam ser dadas aos doentes. Eram muito variadas, pois, além de incluírem "dietas ordinárias”, abriam a possibilidade da existência de outras "dietas extraordinárias”.

No entanto, devemos recordar que estas dietas eram previstas para um hospital de muito maiores dimensões e capacidade financeira de que o hospital de Cabeceiras. Temos assim, e em primeiro lugar, que analisar os livros de receita e despesa para observarmos os géneros que eram adquiridos para a alimentação dos doentes. O seu estudo permite ver quais os géneros comprados: pão de trigo e mistura, leite, legumes, centeio, carne de vaca, vitela, azeite, galinha, milho e produtos de mercearia.

Consultando a tabela de "dietas ordinárias", e ainda as "dietas extraordinárias", do regulamento podemos ver os produtos mais usados. A tabela de "dietas ordinárias” está incluída no regulamento do hospital de Fafe, que também

45 A propósito da iluminação no hospital de São Marcos em Braga veja-se CASTRO, M. F. (1998). “O Hospital de São Marcos, espaços e serviços”. Boletim do Hospital de São Marcos, pp. 20, 111.

46 ASCMCB. Diário da receita e despesa da Santa Casa da Misericórdia de São Miguel de Refojos $n^{\circ}$ 3, 1920-1936, fl. 51v. 
apresenta alguns exemplos de “dietas extraordinárias” que podiam ser prescritas aos enfermos.

Quadro $n^{\circ}$ 31. "Dietas Ordinárias” segundo o Regulamento do hospital de Fafe, adoptado pelo hospital da Misericórdia de Cabeceiras de Basto

\begin{tabular}{|c|c|c|c|c|c|c|c|c|}
\hline 1 & 2 & 3 & 4 & 5 & 6 & 7 & 8 & 9 \\
\hline \multirow[t]{6}{*}{ Almoço } & $\operatorname{Dieta}^{\circ} 1$ & $0,35 \mathrm{l}$ & & & & & & \\
\hline & Dieta $\mathrm{n}^{\circ} 2$ & 0,351 & & & $50 \mathrm{gr}$ & & & \\
\hline & Dieta $n^{\circ} 3$ & & 0,351 & & $100 \mathrm{gr}$ & & & \\
\hline & Dieta $n^{\circ} 4$ & & & 0,351 & $100 \mathrm{gr}$ & & & \\
\hline & Dieta $\mathrm{n}^{\circ} 5$ & & & $0,35 \mathrm{l}$ & $200 \mathrm{gr}$ & & & \\
\hline & Dieta $\mathrm{n}^{\circ} 6$ & & & $0,35 \mathrm{l}$ & $200 \mathrm{gr}$ & & & \\
\hline \multirow[t]{6}{*}{ Jantar } & Dieta $\mathrm{n}^{\circ} 1$ & 0,351 & & & & & & \\
\hline & Dieta $n^{\circ} 2$ & 0,351 & & & $50 \mathrm{gr}$ & & & \\
\hline & Dieta $\mathrm{n}^{\circ} 3$ & & $0,35 \mathrm{l}$ & & $200 \mathrm{gr}$ & & $150 \mathrm{gr}$ & \\
\hline & Dieta $^{\circ} 4$ & & & & $200 \mathrm{gr}$ & $150 \mathrm{gr}$ & & \\
\hline & Dieta $\mathrm{n}^{\circ} 5$ & & & & $200 \mathrm{gr}$ & $150 \mathrm{gr}$ & & \\
\hline & Dieta $\mathrm{n}^{\circ} 6$ & & & & $200 \mathrm{gr}$ & $150 \mathrm{gr}$ & & $50 \mathrm{gr}$ \\
\hline \multirow[t]{6}{*}{ Ceia } & Dieta $\mathrm{n}^{\circ} 1$ & 0,351 & & & & & & \\
\hline & Dieta $\mathrm{n}^{\circ} 2$ & $0,35 \mathrm{l}$ & & & $50 \mathrm{gr}$ & & & \\
\hline & Dieta $\mathrm{n}^{\circ} 3$ & & $0,35 \mathrm{l}$ & & $100 \mathrm{gr}$ & & $150 \mathrm{gr}$ & \\
\hline & Dieta $\mathrm{n}^{\circ} 4$ & & & $0,35 \mathrm{l}$ & $200 \mathrm{gr}$ & $150 \mathrm{gr}$ & & \\
\hline & Dieta $^{\circ} 5$ & & & $0,35 \mathrm{l}$ & $200 \mathrm{gr}$ & $150 \mathrm{gr}$ & & \\
\hline & Dieta $^{\circ} 6$ & & & 0,351 & $200 \mathrm{gr}$ & $150 \mathrm{gr}$ & & \\
\hline \multirow[t]{2}{*}{ Meia-noite e 4 h. da manhã } & Dieta $^{\circ} 1$ & 0,351 & & & & & & \\
\hline & Dieta $^{\circ} 2$ & $0,35 \mathrm{l}$ & & & & & & \\
\hline
\end{tabular}

1, Refeições; 2, Dietas; 3, Caldo de galinha; 4, Caldo de galinha e vaca; 5, Caldo de vaca; 6, Pão; 7, Vaca; 8, Galinha e arroz; 9, Arroz

Fonte: Regulamento do Hospital de São José da vila de Fafe, Braga, Tipografia Lealdade, 1889, p. 27.

As “dietas ordinárias” referidas correspondem a muitos dos produtos alimentares descritos nos livros de receita e despesa. $\mathrm{O}$ arroz era adquirido para ser servido aos internados, devendo estar incluído nos produtos de mercearia. A carne de vitela não aparece nesta tabela, embora nas “refeições extraordinárias” do mesmo regulamento ela surja como uma possibilidade. As despesas da Santa Casa com carne de vitela aparecem como uma das habituais, o que nos faz crer que este produto terá sido preferido pelos responsáveis hospitalares em vez da galinha, a qual é pouco mencionada nas despesas da Santa Casa, e só a partir de 1920.

Café, chá, batatas, massas, peixe, carneiro, ovos, doces e frutas constam das “dietas extraordinárias” previstas no regulamento. Pomos algumas duvidas, sobre se todos estes produtos fossem de facto adquiridos pelo hospital de Cabeceiras. Como já referimos, este era um estabelecimento de menores dimensões e possibilidades financeiras quando comparado com o seu congénere de Fafe. Pensamos que apenas alguns destes géneros estivessem de igual modo incluídos nos produtos de mercearia adquiridos pelo hospital. 
O leite podia acompanhar o café e o chá. A alimentação seria, assim, muito à base de caldos com legumes e carne de vaca ou vitela. O pão estava sempre presente e talvez em certas ocasiões se preparassem torradas. Além do leite, ${ }^{47}$ talvez fosse também servido vinho ${ }^{48}$. Em suma, uma dieta bem mais rica e fortalecedora à qual a grande maioria destes enfermos pobres não teria acesso no seu dia-a-dia. Daí novamente que se perceba parte do sucesso do tratamento destes doentes e que se possa concluir que o hospital da Misericórdia cumpriu os objectivos a que se propunha, apesar de se dever referir que, em alguns anos da década de 1920, teve de restringir bastante a ajuda prestada devido a uma crise inflacionista.

\section{FONTES CONSULTADAS}

ASCMCB - Arquivo da Santa Casa da Misericórdia de Cabeceiras de Basto

Diário da Receita e Despesa da Misericórdia de São Miguel de Refojos, nº 2, 1911-1920.

Diário da Receita e Despesa da Misericórdia de São Miguel de Refojos, nº 3, 1920-1936.

Livro das Actas e Deliberações da Santa Casa da Misericórdia de São Miguel de Refojos, $\mathrm{n}^{\mathrm{o}} 1,1890-1902$.

Livro das visitas dos irmãos de mês ao hospital, 1902-1909.

Livro de Doentes, 1896-1900.

\section{Fontes Impressas}

Regulamento do Hospital de São José da Vila de Fafe, Braga, Tipografia Lealdade, 1889.

\section{BIBLIOGRAFIA}

ABREu, L. (2000). “A especificidade do sistema de assistência pública português, linhas estruturantes”. Arquipélago, História, pp. 417-434.

Abreu, L. (1999). Memórias da alma e do corpo. A Misericórdia de Setúbal na modernidade. Viseu: Palimage Editores.

ARAúso, M. M. L. (2003). "O hospital do Espírito Santo de Portel na época moderna”. Cadernos do Noroeste, pp. 341-409.

${ }^{47}$ Sobre a importância do pão, dos caldos de carne e legumes e do leite nas dietas hospitalares confira-se Jardim, M. D. R. (1996). A Santa Casa da Misericórdia do Funchal, Século XVIII. Funchal: Centro de Estudos de História do Atlântico, pp. 120-121; LOPES, M. A. (1999). Pobreza, assistência e controlo social em Coimbra (1750-1850), vol. II. Coimbra: Palimage Editores, pp. 532533; Abreu, L. (1999). Memórias da alma e do corpo. A Misericórdia de Setúbal na modernidade. Viseu: Palimage Editores, pp. 394-400.

48 Sobre a preparação de torradas e o fornecimento de vinho aos doentes consulte-se (1889). Regulamento do Hospital de São José da Vila de Fafe. Fafe: Tipografia Lealdade, pp. 29-30. 
ÁvilA, J G. (1996). Santa Casa da Misericórdia da Vila das Velas, achegas para a sua história. Vila das Velas: Edição da Misericórdia das Velas.

Calado, R. S. (1936). Origens e vida da Santa Casa da Misericórdia de Torres Vedras. Torres Vedras: Santa Casa da Misericórdia de Torres Vedras.

CARASA Soto, P. (1987). "Câmbios em la tipologia del pauperismo en la crisis del Antiguo Régimen”. Investigaciones históricas. Valladolid: Universidad de Valladolid.

CARASA Soto, P. (1991). História de la beneficência en Castilla y Leon. Poder y pobreza en la sociedad castelhana. Valladolid: Universidad de Valladolid.

CARASA SoTO, P. (2004). "Beneficência y cuestion social: una contaminacion aracaizante". Historia Contemporânea. Valladolid: Serviço Editorial de la Universidad del País Vasco.

CAstro, M. F. (1998). “O Hospital de São Marcos, espaços e serviços”. Boletim do Hospital de São Marcos, pp. 107-119.

Castro, M. F. (2003). A Misericórdia de Braga. Braga: Santa Casa da Misericórdia e autora.

CorreiA, F. S. (1943). “A assistência médica em Portugal durante o século XVI”. Imprensa Médica.

FERnANDES, P. G. C. (1994). “Os vadios de início do século (1901-1906)”. Revista da Faculdade de Letras. História, pp. 333-347.

Goméz Rodriguez, M. S. (1995). El Hospital de la Misericórdia de Toledo en el siglo $X I X$. Toledo: Instituto provincial de investigaciones y estúdios toledanos.

Jardim, M. D. R. (1996). A Santa Casa da Misericórdia do Funchal, Século XVIII. Funchal: Centro de Estudos de História do Atlântico, 1996.

LOPES, M. A. (1999). Pobreza, assistência e controlo social em Coimbra (1750-1850), vol. II. Coimbra: Palimage Editores.

Monteiro, B. R. (2006). O fenómeno de desospitalização e as suas interconexões familiares, comunitárias e sociais., Braga: Instituto de Ciências Sociais tese de doutoramento policopiada.

O’ NeILl, B. J. (1984). Proprietários, lavradores e jornaleiros: desigualdade social numa aldeia transmontana, 1870-1978. Lisboa: Dom Quixote.

PEÑA GonZAlez, P. (1993). La salud y la enfermedad en Huelva en el siglo XIX (18001880). Huelva: Diputacion Provincial de Huelva.

PereirA, M. D. S. (2003). Entre ricos e pobres: a actuação da Santa Casa da Misericórdia de Ponte da Barca (1630-1800). Braga: Universidade do Minho dissertação de mestrado policopiada.

PINTO, M. F. (1999). Os indigentes entre a assistência e a repressão, a outra Lisboa no $1^{o}$ terço do século. Lisboa: Livros Horizonte.

Rosas, F. (1994). “O Estado Novo”. En Mattoso, J. (eds.), História de Portugal vol. VII. Lisboa: Círculo de Leitores.

MAZA ZORILla, E. (1999). Pobreza y beneficência en la España contemporânea (18081936). Barcelona: Ariel Practicum. 
